\title{
Rare postoperative hemorrhage after robotic-assisted pancreatoduodenectomy for pancreatic head cancer: a case report
}

\author{
Jiang-Jiao Zhou ${ }^{1}$, Wen-Hao Chen ${ }^{1}$, Heng Zou ${ }^{1}$, Li Xiong ${ }^{1}$, Xiong-Ying Miao ${ }^{1}$, Chao He ${ }^{1}$, Bo Shu ${ }^{1}$, \\ Yu-Qian Zhou' ${ }^{2}$, De-Liang Liu' ${ }^{2}$ Yu Wen ${ }^{1}$ \\ ${ }^{1}$ Department of General Surgery, ${ }^{2}$ Department of Gastroenterology, The Second Xiangya Hospital, Central South University, Changsha, China \\ Correspondence to: Dr. Yu Wen. Department of General Surgery, The Second Xiangya Hospital, Central South University, Changsha 410011, China. \\ Email: wenyu2861@csu.edu.cn; Dr. De-Liang Liu. Department of Gastroenterology, The Second Xiangya Hospital, Central South University, \\ Changsha 410011, China. Email: deliangliu@csu.edu.cn.
}

\begin{abstract}
Post-pancreaticoduodenectomy hemorrhage is a life-threatening complication that occurs in $2-10 \%$ of patients. The most common location for post-pancreaticoduodenectomy hemorrhage is the gastroduodenal artery stump. Nonetheless, unusual sources of hemorrhage, which are hard to locate, exist. Here, we report a rare postoperative hemorrhage after robotic-assisted pancreatoduodenectomy for pancreatic head cancer. A 67-year-old man presenting with appetite loss, general fatigue and painless jaundice was admitted to our ward. The patient had an elevated level of carbohydrate antigen 19-9 $(50 \mathrm{U} / \mathrm{mL})$. Computed tomography scan revealed a $17-\mathrm{mm}$ wide low-density area in the uncinate process of the pancreas. Magnetic resonance cholangiopancreatography showed the dilation of bile and pancreatic ducts. Robotic-assisted pancreaticoduodenectomy was performed on the patient by using the da Vinci Model S Surgical System. On postoperative days 5 and 6, the patient vomited blood, and bloody fluid was observed in the drainage. Emergent gastroscopic examination was performed and revealed a large amount of hematocele in the stomach. On postoperative day 6, emergency operation was undertaken, and the output jejunal loop was found to have intussuscepted in the stomach. This is the first case report of output jejunal loop intussusception in the stomach that consequently caused hemorrhage after robotic-assisted pancreaticoduodenectomy for pancreatic head cancer.
\end{abstract}

Keywords: Robotic-assisted pancreatoduodenectomy (RAPD); complication; hemorrhage; intussusception; case report

Submitted May 08, 2020. Accepted for publication Jul 14, 2020.

doi: 10.21037/jgo-20-207

View this article at: http://dx.doi.org/10.21037/jgo-20-207

\section{Introduction}

Pancreatic cancer is one of the most lethal malignancies and is associated with very poor overall survival (1). Surgery remains the only option for the possibility of cure for patients with localized pancreatic cancer. Pancreatoduodenectomy (PD) is the major surgical option for pancreatic head cancers. With the development of laparoscopic surgical skills, internal closure devices, and energy systems, robotic-assisted pancreatoduodenectomy (RAPD) can be safely performed in well-selected patients by well-trained teams with extensive experience in open PD $(2,3)$. The perioperative mortality of pancreatic surgery, especially in high-volume centers, has decreased dramatically to less than $5 \%$ in the last two decades (4). However, the rate of the occurrence of postoperative complications remains high (5). The most common complications of $\mathrm{PD}$ are postoperative infections, delayed gastric emptying, hemorrhage, and anastomotic insufficiencies (pancreatic, biliary, gastric/duodenal, and enteral) (6,7). Among patients who had undergone PD, 

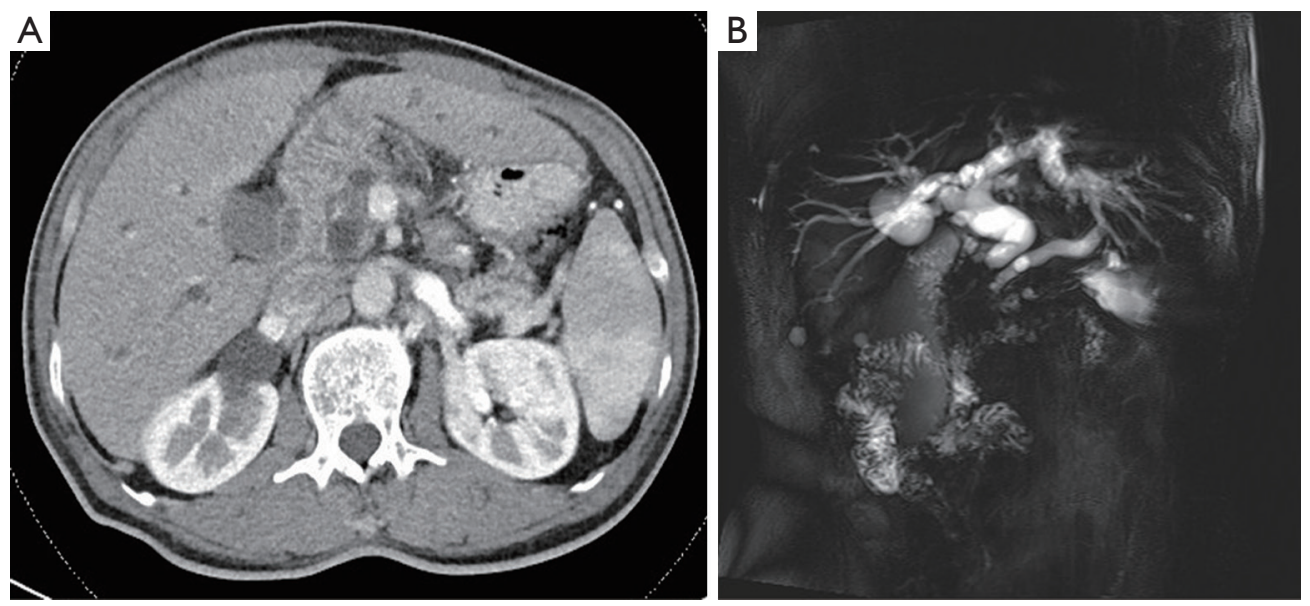

Figure 1 Imaging findings. (A) Preoperative computed tomography showed a 17-mm wide low-density area in the uncinate process of the pancreas; (B) magnetic resonance cholangiopancreatography revealed the dilatation of intrahepatic and extrahepatic bile ducts and pancreatic duct.

approximately $2-10 \%$ develop post-pancreatectomy hemorrhage $(\mathrm{PPH})$, a life-threatening complication with the reported mortality rate of $20-50 \%(8,9)$. Here, we report a male patient who experienced $\mathrm{PPH}$ with a very rare cause after RAPD. We present the following article in accordance with the CARE reporting checklist. Available at http://dx.doi.org/10.21037/jgo-20-207.

\section{Case presentation}

\section{Chief complaints}

A 67-year-old man presenting with appetite loss, general fatigue, and painless jaundice was admitted to our ward.

\section{History of past illness}

The patient had no previous noteworthy medical history.

\section{Personal and family bistory}

The patient did not smoke tobacco or consume alcohol. Relevant personal or family history did not exist.

\section{Physical examination}

The patient had yellow skin and sclera. The patient's abdomen was soft and flat without spontaneous pain or tenderness.

\section{Laboratory examinations}

The patient's laboratory results were as follows: hemoglobin $13.5 \mathrm{~g} / \mathrm{dL}$, total bilirubin $216.6 \mu \mathrm{mol} / \mathrm{L}$, direct bilirubin $191.5 \mu \mathrm{mol} / \mathrm{L}$, albumin $34.6 \mathrm{~g} / \mathrm{L}$, and immunoglobulin $\mathrm{G}$ $40.901 \mathrm{~g} / \mathrm{L}$. Tumor markers were normal except for an elevated level of carbohydrate antigen 19-9 $(50 \mathrm{U} / \mathrm{mL})$.

\section{Imaging examinations}

Computed tomography (CT) scan revealed a $17-\mathrm{mm}$ wide low-density area in the uncinate process of the pancreas (Figure 1A). Magnetic resonance cholangiopancreatography showed the dilation of bile and pancreatic ducts (Figure 1B).

\section{Treatment}

RAPD was performed by using the da Vinci Model S Surgical System (Intuitive Surgical, Sunnyvale, CA, USA) (Figure 2A). Digestive tract reconstruction was performed via Child's method. The order of anastomosis was pancreaticojejunostomy, hepaticojejunostomy, and gastrojejunostomy. Gastrointestinal anastomosis reconstruction was conducted behind the colon. Pancreaticojejunostomy was performed via the pancreatic duct to the jejunal mucosa. Biliary anastomosis was continuously sutured with the absorbable barbed wire, and a $\mathrm{T}$ tube was not placed in the anastomosis. Gastrointestinal anastomosis was carried out with a linear cutting occluder 

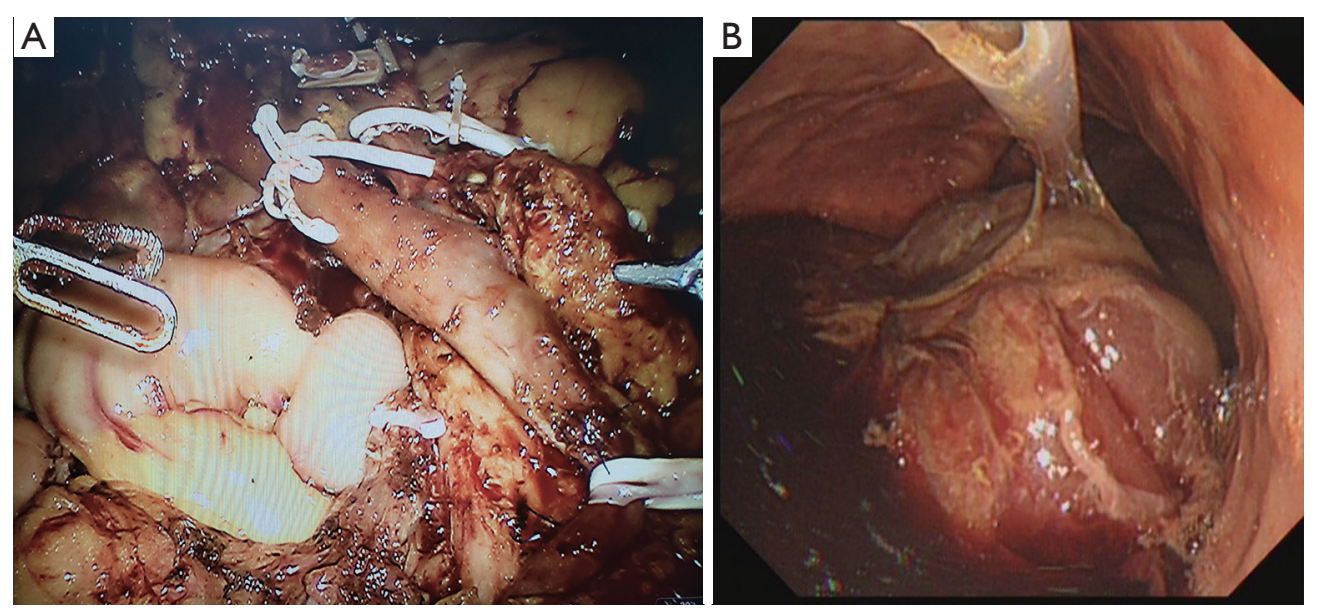

Figure 2 Intraoperative findings and gastroscopic examination. (A) Intraoperative findings for robotic-assisted pancreatoduodenectomy; (B) gastroscopic examination showed a large amount of hematocele and congestive and edematous intestine in the stomach.
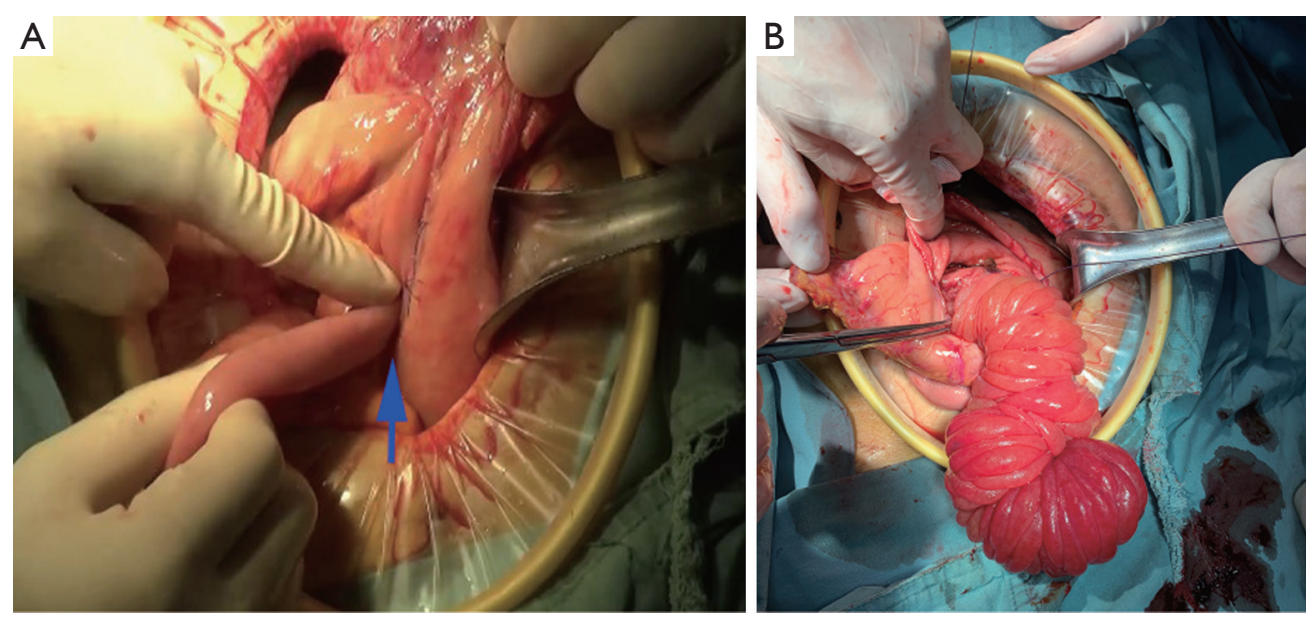

Figure 3 Emergency operation. (A) Output jejunal loop was found intussuscepted in the stomach; (B) long section of small intestine was found inside the stomach.

with side-to-side anastomosis. After the surgery, the patient was admitted to the inpatient ward.

On postoperative days (PODs) 1 to 3 , the patient was in stable condition without increased amylase in exudate fluid from drainage. On POD 4, the patient intermittently vomited gastric content. On PODs 5 and 6, the patient vomited blood, and bloody fluid was observed in the drainage. Epigastric paroxysmal abdominal pain existed but lacked peritonitis signs. The CT angiography of the superior mesenteric artery was immediately performed, but the hemorrhage source could not be confirmed. The patient experienced continuous blood vomiting and declined hemoglobin. Emergent gastroscopic examination was performed, and a large amount of hematocele was found in the stomach (Figure 2B). Congestive and edematous intestine was present in the stomach (Figure $2 B$ ).

On POD 6, emergency operation was performed. The output jejunal loop was found to have intussuscepted in the stomach (Figure 3A). After gastrotomy, a long section of the small intestine was found inside the stomach (Figure $3 B)$. Reconstruction after partial gastrectomy and partial intestinal resection was performed.

\section{Final diagnosis}

Pancreatic ductal adenocarcinoma (T2N0M0, stage I B). 


\section{Outcome and follow-up}

After exploratory laparotomy, the patient recovered well and was discharged 10 days after operation. Hemorrhage was no longer observed during the follow-up. All procedures performed in studies involving human participants were in accordance with the ethical standards of the institutional and/or national research committee(s) and with the Helsinki Declaration (as revised in 2013). Written informed consent was obtained from the patient for publication of this study and any accompanying images.

\section{Discussion}

PD is a standard procedure for pancreatic head cancer. Considerable progress has been made in the safety of $\mathrm{PD}$ due to the ingenuity of surgeons and advances in surgical instruments. Nonetheless, the occurrence rate of postoperative complications is high.

$\mathrm{PPH}$ is the most common and dreaded complication after PD and is associated with mortality rates of as high as $21 \%$ (9). A recent study reported that $3.8 \%$ of 105 patients who underwent robotic PD experienced PPH (10). Another recent study reported by Shi et al. showed postoperative bleeding rates of $4.3 \%$ after RAPD (11). The International Study Group for Pancreatic Surgery divided PPH cases into early hemorrhage occurring within $24 \mathrm{~h}$ after operation and late hemorrhage beyond $24 \mathrm{~h}$ after operation to facilitate the standardized reporting and study of this complication (8). Delayed PPH is among the most devastating postoperative complications for PD. A review of a prospective database of 1,669 consecutive pancreatic resections showed that the mortality rate among patients presenting with delayed hemorrhage is nearly $50 \%$ (12).

The diagnosis of PPH may be confirmed via upper gastrointestinal endoscopy, angiography, CT, or reoperation. However, subsequent management remains controversial. Given that early $\mathrm{PPH}$ is often attributed to technical failure or underlying coagulopathy, most surgeons advocate for reoperation, whereas delayed $\mathrm{PPH}$ is usually secondary to complications, such as abscess formation, vessel erosions, pancreatic fistulas, ulcerations at anastomosis sites, or pseudoaneurysm development. For the treatment of delayed hemorrhage, some groups advocate for operative intervention, whereas others support an interventional or endoscopic approach whenever possible (12-14). In general, accessing or controlling hemorrhages is difficult because of pancreatic leakage or infection in the operative field for reoperation. In our case, a non-operative approach to control the hemorrhage was initially given high priority. However, operative intervention was undertaken eventually.

Given the high mortality associated with $\mathrm{PPH}$, identifying the sources of a hemorrhage is valuable. $\mathrm{PPH}$ may originate from the following (15): (I) arterial or venous vessels; (II) anastomotic stoma (gastroenteric, jejunojejunal, or pancreaticoenteric); (III) resection areas (e.g., pancreas stump or retroperitoneum); (IV) gastric/duodenal ulcer or diffuse gastritis; (V) eroded and ruptured pseudoaneurysms; or (VI) hemobilia from previously placed endobiliary stents. Dumitru et al. reported an uncommon cause of delayed hemorrhage after PD caused by a splenic artery pseudoaneurysm (16). To our knowledge, this is the first case report of output jejunal loop intussusception in the stomach that consequently caused PPH after PD.

The identification of patients who are at risk for $\mathrm{PPH}$ is clinically meaningful. A previous study reported that age, postoperative pancreatic fistulas (POPFs), and nutritional risk indexes are risk factors for PPH (17). Another study conducted multivariate modeling and identified several risk factors, including advanced age, increased body mass index, intraoperative transfusion, portal venous and multivisceral resections, and POPFs, for severe PPH (18). Izumo et al. found that the absence of diabetes mellitus and POPFs are risk factors for PPH in patients who underwent PD (19). In contrast to patients in these studies, our patient lacked POPFs.

Output jejunal loop intussusception in the stomach after PD is rare. Prolonged pneumoperitoneum caused by using the da Vinci robot might be one of the reasons for the intussusception of the output loop in the stomach in our case. Repeated vomiting and increased positive pressure within the abdomen might be other reasons.

\section{Conclusions}

This is the first case report of output jejunal loop intussusception in the stomach that consequently caused PPH after RAPD for pancreatic head cancer.

\section{Acknowledgments}

Funding: This study was supported by the Big Data Project of Xiangya Medical School, Central South University, the grants from the Innovation and Development Project of Development and Reform Commission of Hunan Province 
\{No. [2019]875\}, the Scientific and Technological Progress and Innovation Project of Communications Department of Hunan Province \{No. [2018]234(201835)\}.

\section{Footnote}

Reporting Checklist: The authors have completed the CARE reporting checklist. Available at http://dx.doi.org/10.21037/ jgo-20-207

Conflicts of Interest: All authors have completed the ICMJE uniform disclosure form (available at http://dx.doi. org/10.21037/jgo-20-207). The authors have no conflicts of interest to declare.

Ethical Statement: The authors are accountable for all aspects of the work in ensuring that questions related to the accuracy or integrity of any part of the work are appropriately investigated and resolved. All procedures performed in studies involving human participants were in accordance with the ethical standards of the institutional and/or national research committee(s) and with the Helsinki Declaration (as revised in 2013). Written informed consent was obtained from the patient for publication of this study and any accompanying images.

Open Access Statement: This is an Open Access article distributed in accordance with the Creative Commons Attribution-NonCommercial-NoDerivs 4.0 International License (CC BY-NC-ND 4.0), which permits the noncommercial replication and distribution of the article with the strict proviso that no changes or edits are made and the original work is properly cited (including links to both the formal publication through the relevant DOI and the license). See: https://creativecommons.org/licenses/by-nc-nd/4.0/.

\section{References}

1. Siegel RL, Miller KD, Jemal A. Cancer statistics, 2020. CA Cancer J Clin 2020;70:7-30.

2. Kamarajah SK, Bundred JR, Marc OS, et al. A systematic review and network meta-analysis of different surgical approaches for pancreaticoduodenectomy. HPB (Oxford) 2020;22:329-39.

3. Kamarajah SK, Bundred J, Marc OS, et al. Robotic versus conventional laparoscopic pancreaticoduodenectomy a systematic review and meta-analysis. Eur J Surg Oncol 2020;46:6-14.
4. Pedrazzoli S. Pancreatoduodenectomy (PD) and postoperative pancreatic fistula (POPF): A systematic review and analysis of the POPF-related mortality rate in 60,739 patients retrieved from the English literature published between 1990 and 2015. Medicine (Baltimore) 2017;96:e6858.

5. Tan E, Song J, Lam S, et al. Postoperative outcomes in elderly patients undergoing pancreatic resection for pancreatic adenocarcinoma: A systematic review and metaanalysis. Int J Surg 2019;72:59-68.

6. Bhosale P, Fleming J, Balachandran A, et al. Complications of Whipple surgery: imaging analysis. Abdom Imaging 2013;38:273-84.

7. DeOliveira ML, Winter JM, Schafer M, et al. Assessment of complications after pancreatic surgery: A novel grading system applied to 633 patients undergoing pancreaticoduodenectomy. Ann Surg 2006;244:931-7.

8. Wente MN, Veit JA, Bassi C, et al. Postpancreatectomy hemorrhage (PPH): an International Study Group of Pancreatic Surgery (ISGPS) definition. Surgery 2007;142:20-5.

9. Floortje van Oosten A, Smits FJ, van den Heuvel DAF, et al. Diagnosis and management of postpancreatectomy hemorrhage: a systematic review and meta-analysis. HPB (Oxford) 2019;21:953-61.

10. Shyr BU, Shyr BS, Chen SC, et al. Operative results and patient satisfaction after robotic pancreaticoduodenectomy. Asian J Surg 2020;43:519-25.

11. Shi Y, Jin J, Qiu W, et al. Short-term Outcomes After Robot-Assisted vs Open Pancreaticoduodenectomy After the Learning Curve. JAMA Surg 2020;155:389-94.

12. Yekebas EF, Wolfram L, Cataldegirmen G, et al. Postpancreatectomy hemorrhage: diagnosis and treatment: an analysis in 1669 consecutive pancreatic resections. Ann Surg 2007;246:269-80.

13. Blanc T, Cortes A, Goere D, et al. Hemorrhage after pancreaticoduodenectomy: when is surgery still indicated? Am J Surg 2007;194:3-9.

14. Correa-Gallego C, Brennan MF, D'Angelica MI, et al. Contemporary experience with postpancreatectomy hemorrhage: results of 1,122 patients resected between 2006 and 2011. J Am Coll Surg 2012;215:616-21.

15. Wolk S, Grutzmann R, Rahbari NN, et al. Management of clinically relevant postpancreatectomy hemorrhage (PPH) over two decades - A comparative study of 1450 consecutive patients undergoing pancreatic resection. Pancreatology 2017;17:943-50.

16. Dumitru R, Carbunaru A, Grasu M, et al. Pseudoaneurysm 
of the splenic artery - an uncommon cause of delayed hemorrhage after pancreaticoduodenectomy. Ann Hepatobiliary Pancreat Surg 2016;20:204-10.

17. Darnis B, Lebeau R, Chopin-Laly X, et al.

Postpancreatectomy hemorrhage $(\mathrm{PPH})$ : predictors and management from a prospective database. Langenbecks Arch Surg 2013;398:441-8.

Cite this article as: Zhou JJ, Chen WH, Zou H, Xiong L, Miao XY, He C, Shu B, Zhou YQ, Liu DL, Wen Y. Rare postoperative hemorrhage after robotic-assisted pancreatoduodenectomy for pancreatic head cancer: a case report. J Gastrointest Oncol 2020;11(4):820-825. doi: 10.21037/ jgo-20-207
18. Wellner UF, Kulemann B, Lapshyn H, et al.

Postpancreatectomy hemorrhage--incidence, treatment, and risk factors in over 1,000 pancreatic resections. J Gastrointest Surg 2014;18:464-75.

19. Izumo W, Higuchi R, Yazawa T, et al. Evaluation of preoperative risk factors for postpancreatectomy hemorrhage. Langenbecks Arch Surg 2019;404:967-74. 